\title{
T-TO-C MOVEMENT: SyNTACTIC LICENSING AND DIALECTAL VARIATION ${ }^{1}$

\author{
(Movimento de T para C: Licenciamento \\ sintático e variação dialectal)
}

Georgios IOANNOU (Profesor Asistente, Universidad de Chile, Departamento de Lingüústica)

\begin{abstract}
This paper intends to extend and elaborate the line of research initiated by Pesetsky and Torrego $(2001,2004)$ on the role of Tense as a licensing condition over phrasal extraction. In the context of the operation of CP-raising, it re-interprets some instances of T-to-C movement as having not a licensing but a blocking effect over CP-extraction. T-to-C Movement then is analysed as part of an integral operational cycle of gradual saturation comprizing head movement as well as head-agreement. This extended paradigm is analyzed as various degrees of operational completeness, correponding to degrees of "specificity". Within this operational hierarchy of featural specificity resides the mechanism that "opens" or "closes" the syntactic path for phrasal movement to apply. Drawing on data from Belfast English, it is observed that dialectal variation takes place on particular points that lie lower in this hierarchy, in other words at a derivational point of operational "under-specification".
\end{abstract}

Key-words: T-to-C movement; head movement; optionality; (under)-specification.

Resumo: Este trabalho tem a intenção de estender e elaborar a linha de pesquisa iniciada por Pesetsky e Torrego $(2001,2004)$ sobre o papel de Tempo como condição de licenciamento de extração de sintagmas. No contexto de elevação de CP, re-interpreta alguns exemplos de movimento de $T$ para $C$ não como possuindo um efeito de licenciamento, mas como um efeito de bloqueio sobre o extracção do CP. Então movimento de T para $C$ é analisado como parte integrante de um ciclo operacional de saturação gradual que compreende o movimento da cabeça, bem como acordo entre cabeças. Este paradigma estendido é analisado como vários graus de completude operacional, correponding a graus de "especificação". Dentro dessa bierarquia operacional da especificaşão de traços reside o mecanismo que "abre" ou "fecha" o caminho para a aplicação de movimento sintático de sintagmas. Baseando-se em dados de Inglês do Belfast, observa-se que a variação dialetal ocorre em pontos que se encontram abaixo na bierarquia, em outras palavras, em um ponto derivacional de "sub-especificação" operacional.

Palavras-chave: movimento de T para C; movimento da cabeça; opcionalidade; (sub) especificação.

1. I would like to thank the two anonymous reviewers for their useful comments and remarks. 


\section{INTRODUCTION}

Movement in generative syntactic theory has been assumed to be a pervasive phenomenon wherby multiple instances of a single grammatical element appear distributed within the structure. It is a genaralised property of natural languages and essentially describes the fact that grammatical occurrences pronounced in one position are also interpreted as if they were somewhere else (ef.: Chomsky 2002).

Various grammatical phenomena can illustrate this generalised property. In passive constructions, for example, the object raises from V-complement position in SPEC-TP:

(1)

Something is held by the thief.

The above sentence is also understood as "the thief holds something", in other words as if the object retains its local relation with the verb, with the raised subject being linked with effects of specificity and new information.

Another example is represented by wh-movement, where again an argument is also understood as interpreted in its original position. This dual occurence gives rise to the binding relation between the dislocated and the original copy of the wh-phrase, a relation deemed to be necessary for the generation of the correspondent logical form pertaining to interrogative interpretation (Chomsky 1981):

(2) What does the thief hold?

For what $\mathrm{x}$, the thief holds $\mathrm{x}$ ?

A final example comes from Auxiliary Inversion in interrogative clauses where the specification of Tense surfaces higher than where it appears overtly in declarative clauses, what has otherwise been formulated as T-to-C Movement:

(3) The thief stole the statue.

Did the thief steal the statue? 
As we will see below, a specific challenge is met in the context of treating T-to-C Movement as a syntactic operation interpretatively relevant, in connection to the partial applicability of T-to-C Movement.

A further question that arises in relation with movement operations in general is their trigger. Ultimately, the issue has to address the aforementioned link between a formal syntactic trigger and interpretative results. The link was first envisaged in Chomsky (2002), in the context of a possible connection between interpretable features as the trigger of Move on the one hand and externally imposed conditions on the language faculty on the other.

How plausible is this connection? It seems that for the case of A-Movement like subject raising it is (ef.: Lasnik and Saito 1999). Long distance subject movement seems to be intrinsically unbounded until finding a landing site eligible to enter into an Agree relation with it:

(4) The thief appears [ to have been arrested

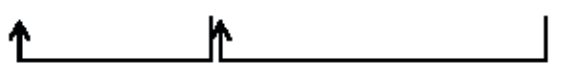

An assumption in minimalist analyses that follows as a corollary of the conclusion that movemet is triggered is that this cannot be optional, but always triggered by the featural properties included in the syntactic derivation itself (ef.: Chomsky 2000, 2001). These properties, themselves part of the matrices constituting the atomic elements entering a derivation, fall into two categories: interpretable $(i-\mathrm{F})$ and uninterpretable $(u-\mathrm{F})$. The former make a contribution to the interpretation of the items carrying them (e.g. Tense), though the latter do not (e.g. the person/number morphology on verbs). As shown in (5), they are supposed to play a role in implementing the licensing of phrasal movement, through matching between an interpretable and an uninterpretable feature of the same type: 
(5)

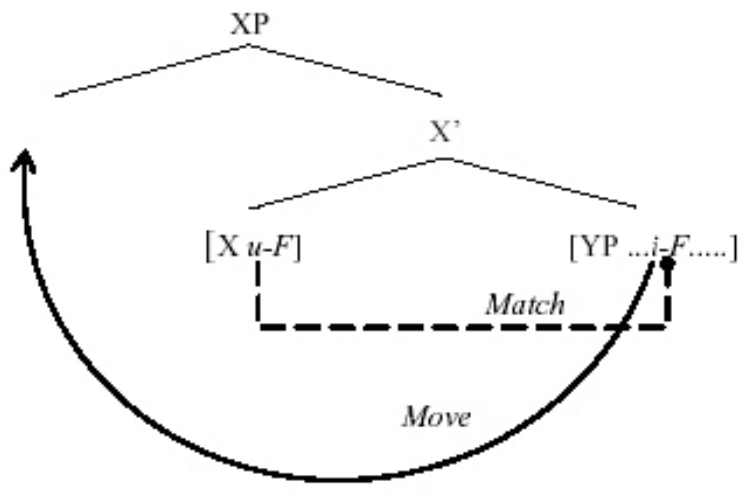

This symmetrical featural correspondence between probe and goal in terms of feature type as the operational context of Match and the generalisation of this symmetry as a precondition over all types of Move led to the assumption that wh-movement must have a quasi morphological trigger (ef.: Rizzi 1997) too. A $u$-wh Probe in a head then carries a mirror image of an interpretable $w h$-feature of a wh-phrase. Accordingly, T-to-C movement manifested as auxiliary inversion is also triggered by an uninterpretable feature of Tense carried by the head in which Tense moves. Both uninterpretable features, namely $u$-wh and $u$-T, have to be eliminated before the derivational cycle to which they belong comes to an end (Chomsky 2001). The featural correspondence then in a clause where T-to-C Movement applies is as follows:

(6) What does the thief hold?

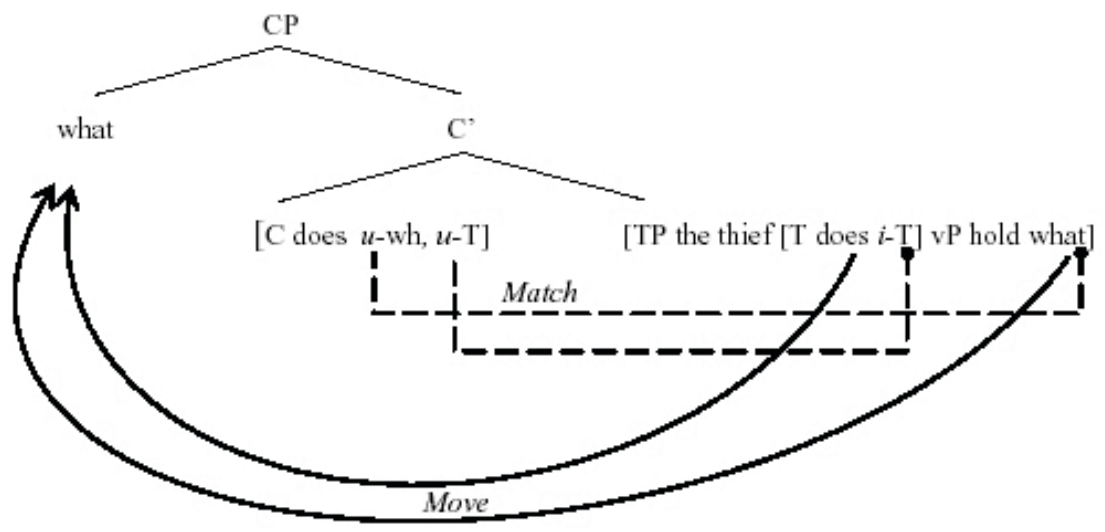


One of the problems surrounding the place of T-to-C Movement in syntax is its partial applicability. For example, in embedded clauses in Standard English (SE henceforth), it is not manifested:

(7) *I don't know what did the thief hold.

Crucially, there are two premises running through the relevant discussion to which the evaluation of the issue is ultimately reduced; one is the ban on partial applicability/optionality, and the other is the underlying assumption that less is better, in other words that reducing as much as possible the number of primitives in our technical apparatus is consonant with the assumption that the system operates optimally (ef.: Chomsky 1995, Hinzen 2006). In other words, how can we extend the applicability of a phenomenon not uniformly observed, at the same time extending our technical apparatus to the minimum possible? The difficulty that a neat and theoretically appealing view of Language as an optimal system meets is precisely the untidy and asymmetrical phenomena included in an otherwise rigorous theoretical paradigm.

The present work intends to take a closer look at the notion of licensing attributed to T-to-C Movement. It evaluates its syntactic relevance, reexamining the position of non-total applicability of T-to-C movement, in the context of wh-embedding and CP-raising. It is organized as follows: Section 2 reviews and evaluates the generalized licensing effect on phrasal extraction attributed to Tense in the work of Pesetsky and Torrego 2001, 2004 (henceforth P\&T 2001, P\&T 2004 respectively) and it points at the problems that an unqualified generalization faces in the case of embedded clauses. Section 3 first qualifies this generalization, re-interpreting T-to-C Movement as a blocking mechanism over wh-CP extraction. It draws a sharp distinction between T-to-C Movement and Complementizer-Tense Match, attributing distinct operational outcome to each of them. It then looks at the consequences of such a qualification that hints at a more elaborate hierarchy of syntactic dependences. It employs the notion of "featural specificity" between head pairs, formalising head relations as modular cycles of various degrees of operational completness. It then sees how phrasal movement is contingent upon this degree of completeness and how mere Match between $\mathrm{C}$ and $\mathrm{T}$, representing a mid-stage of this operational cycle, licenses dialectal variation. This is shown to be so because 
C-T Match lies "higher" in this hierarchy as less specific. Section 4 presents the conclusions of the analysis.

\section{The account of Pesetsky and Torrego (2001, 2004)}

\subsection{Syntactic license and Tense}

Pesetsky and Torrego $(2001,2004)$ try to illuminate the theory of structural Case as a feature of instrumental importance both to the distribution as well as the construction of the grammatical objects as such. With Case being linked to what earlier years had been formulated under considerations of argumental visibility (ef.: Chomsky 1981), P\&T's work suggests that the distribution of the formal feature of Case inside arguments interacts strongly with the external distribution of these arguments (P\&T 2004). They try then to account for the raising properties of subjects as well as CPs headed by "that", assuming that what drives their raising is that they are both headed uniformly by a Tense feature: uninterpretable in the case of subjects, interpretable in the case of CPs. In the light of this identification between Case and Tense, they generalize on the ability of a Tense feature to render a syntactic object extractable.

What this paper argues is that this distinction drawn between $u$-T and $i-T$ is actually part of a more comprehensive operational cycle that comprises Agree and Move as degrees of a featural saturation reflected on the ability of a grammatical object to raise. Let's then first look briefly at the argumentation presented in $\mathrm{P} \& \mathrm{~T}$ and the basic assumptions they make that are relevant to my analysis.

P\&T's analysis supposes that the implementation of Match must obey more general principles that are subject to optimality considerations. In accord with Relativized Minimality (Rizzi 1990), P\&T follow Chomsky (1995) in suggesting that closeness is an optimal metric of how Match between relevant elements proceeds:

(8) Attract Closest F (ACF)

If a head $\mathrm{K}$ attracts Feature $\mathrm{F}$ on $\mathrm{X}$, no constituent that bears $\mathrm{F}$ is closer to $\mathrm{K}$ than $\mathrm{X}$. 
In this light, P\&T unify head and phrasal movement, applying the featural analysis of Match to the movement of $\mathrm{T}$ into $\mathrm{C}$ in interrogative clauses. According to this view, an interrogative $\mathrm{C}$ carries two uninterpretable features: $u$-wh and $u$-T, as a corollary of the observed movement of the wh-phrase to SPEC-CP and of Tense into C (manifested as do-support) in non-subject wh-questions:

(9) What does the thief hold?

[CP what $[\mathrm{C}$ does $t-w h, t-T]$ [TP the thief $[\mathrm{T} i-T][\mathrm{vP}$ hold what $]]]^{2}$

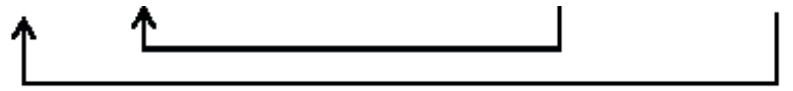

Let's see now how P\&T account for the absence of T-to-C Movement in wh-interrogatives like (10):

(10) *Who does bold the suitcase?

Their reasoning implicitly assumes that in accord with Structural Uniformity (Rizzi 1988, 2000) a) C in interrogatives uniformly carries a $u$-wh and a $u$-T feature and b) movement of the wh-subject to SPEC-CP does take place (contra Chomsky 1986, Radford 1997, Agbayani 2000). Then invoking closeness as an indispensable prerequisite of Match implies that $u$ - $\mathrm{T}$ in $\mathrm{C}$ must be satisfied by the closest candidate. Given that $i-\mathrm{T}$ is not attracted, the only remaining possible candidate satisfying closeness is the subject itself. What is traditionally held is that the featural composition of a DP only contains a pair of $i-\phi$ features (number and person) and a $u$-Case feature. As $i-\phi$ features are well-defined as nominal interpretable features and so unlikely to be matched by $u$-T, $\mathrm{P} \& \mathrm{~T}$ propose that what is matched by $u$-T in $\mathrm{C}$ as a goal is $u$-Case itself, thus drawing a featural identification between Nominative $u$-Case on $\mathrm{D}$ and $u$-T. They argue that in accord with a more general Economy Principle that syntactic operations must adhere to, the equidistance that in principle holds between $\mathrm{C}$ and any

2. P\&T do not consider SPEC-vP an intermediate escape hatch for Wh-Movement, at that time an assumption not fully adopted (although already present in Barriers, Chomsky 1986). In cases where the choice does not materially affect my analysis, this intermediate step will be omitted for clarity of exposition. 
category contained within TP render both SPEC-TP and T in principle equidistant:

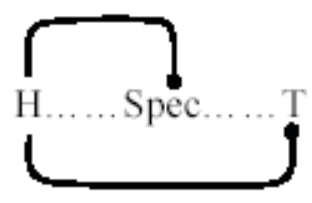

The one-step operation of attracting SPEC-TP is evaluated as more economical simply because it statisfies $u$-Wh and $u$-T features in $\mathrm{C}$ in one derivational step. An effect subsequently formulated as a quasi anti-locality effect in Abels (2003) is at stake, blocking Match with the SPEC of a complement, an effect formulated in P\&T (2001) as follows:

(12) Head Movement Generalization

Suppose a Head $\mathrm{H}$ attracts a feature of XP as part of a Movement operation.

i. If XP is the complement of $\mathrm{H}$, copy the head of XP into the local domain of $\mathrm{H}$.

ii. Otherwise, copy XP into the local domain of $\mathrm{H}$.

But why should a $u$-T feature be present in $\mathrm{C}$ in Wh-Interrogatives at all? P\&T offer an account based on Richard's Principle of Minimal Compliance PMC (Richards 1997, 2001), stating that once an instance of movement has obeyed a constraint on the distance between source and target, other instances of movement do not need to obey this constraint. Generalizing this principle as Attract Closest $\mathrm{X}(A C X), \mathrm{P} \& \mathrm{~T}$ argue that Internal Merge of a non-subject $w h$-phrase is impossible if $i$ - $T$ has not previously been attracted, with $C$ being unable to attract what before it attracts will:

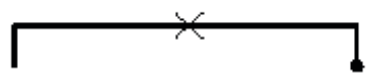

(13) $\{C$ the thief (will) (steal what \})

Attraction of will then enables $C$ to probe further and match what. Essentially, ACX refers to constituents and not to features. This is the way P\&T's analysis accounts for the seemingly vacuous movement of whsubjects as well as T-to-C Movement, under the view that head and phrasal Movement comply to identical metrics of closeness. 
Beyond the subject/non-subject operational mismatches, there is a further asymmetry bearing on the observations about T-to-C Movement, met in the context of wh-embedding. In SE, embedded wh-interrogatives do not display T-to-C Movement:

(14) I really don't know (what the thief had taken)

(15) *I really don't know (what had the thief taken)

But if T-to-C Movement were a necessary condition on the attraction of a wh-object, then we would expect it to be obligatorily satisfied somehow in (14) too. Otherwise the generalisation of ACX and the way this can be overridden remain unexplained.

In support of their generalization, $\mathrm{P} \& \mathrm{~T}$ appeal to data from Belfast English (BE henceforth; ef.: Henry 1995), where T-to-C Movement applies even in embedded contexts, concomitantly with wh-movement:

(16) I don't know twhat did the thief steal

(17) What do you think (did the thief steal ?)

(18) I don't know (what did Mary say (would Bill claim (did the thief steal HFH

According to P\&T, (16-18) support the validity of the generalisation of the application of T-to-C Movement in every case where an interrogative wh-phrase, lying beyond the local domain of $\mathrm{C}$, has been attracted. Addressing the absence of T-to-C Movement in SE embedded contexts, $\mathrm{P} \& \mathrm{~T}$ take their assumptions one step further, proposing that the observed that-trace asymmetry found in embedded clauses from where a wh-phrase has been extracted is essentially a manifestation of the T-to- $\mathrm{C}$ asymmetry in disguise, taking COMP-that to be an instance of Tense that has moved into COMP from $\mathrm{T}$ :

(19) What do you think ( $($ that $)$ the thief (T has, i-T\} stolen ?)

\section{个}

(20) Who do you think $\{(*$ that $)$ (T has, i-T\} stolen the statuette?

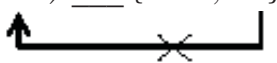


In (19) what has moved from VP-Complement position and COMP-that is allowed to occur in C. In (20), the subject who has been extracted from SPEC-TP position and the presence of COMP-that is barred ${ }^{3}$.

All the above inevitably extends the application of ACX to both declarative and interrogative clauses, with the occurrence of a $u$ - $\mathrm{T}$ in $\mathrm{C}$ postulated in $\mathrm{P} \& \mathrm{~T}$ for any interrogative or declarative embedded clause introduced by COMP-that. T-to-C movement then must also apply in clauses like (21) where a declarative embedded clause is introduced by that:

(21) I really believe (that the thief left with a black suitcase).

Now, take the following clause where a that-CP has raised into the matrix clause:

(22) (That the thief stole the statuette\} makes me upset.

It seems plausible to extend P\&T's assumptions as bearing on CPraising. Thus $\mathrm{P} \& \mathrm{~T}$ account for the ungrammatucality of (23) as an obviation of T-to-C movement as a genaralized licensing condition:

(23) *(the thief stole the statuette) makes me upset.

In this sense, the contrast between (22) and (23) corresponds to the distinction between $u$ - $\mathrm{T}$ and $i$-T, and the ungrammaticality of (23) is precisely induced by the absence of an instance of Tense in C. But the question to be addressed first is: how plausible is the hypothesis that COMP-that realizes T's movement into $\mathrm{C}$ in free variation with T-to-C Movement?

The evaluation of a generalized and unqualified attracting $u$ - $\mathrm{T}$ in $\mathrm{C}$ must first address in some detail the opeational aspects of its plausibility. Taking into consideration that the initial motivation for it is a licensing condition on the attraction of a wh-phrase that would otherwise remain inaccessible to C's probing, the unqualified extension of the data to

3. Sobin (2002) shows how "that"-trace effects can be attenuated by intervening adverbs. See P\&T (2001) for an account of these attenuations. 
declarative clauses weakens the plausibility of the initial proposal. Such a generalization dispenses with two properties that ideally one would expect to hold of the Conceptual-Intentional (C-I) interface as well as the Articulatory-Perceptual (A-P) one: a) the systematic co-alignment between structural and interpretive effects, and b) the closest possible distance between syntactic representations and surfacing phonetic outcomes.

Regarding the syntactic plausibility of the generalization of T-to-C Movement as an unqualified licensing condition over extraction, I observe that the application of T-to-C Movement as that-to-C Movement in the case of the that-trace phenomenon would not refer to attraction, but clearly to extraction. This is obvious in (24) where COMP-that is disallowed even in non-subject wh-Interrogatives when the wh-expression does not move beyond the embedded complementizer. Compare (24) with (25-26):

(24) *I didn't say (what that the thief has stolen f.

(25) What did you say (that the thief has stolen ?

(26) What I didn't say (that the thief has stolen fis the tablet.

Crucially, COMP-that and Tense in $\mathrm{C}$ do not co-occur in free variation with a wh-expression, as would be expected if that were $i$-T. Some more elaborate architecture is at stake. Although some identity between COMPthat and Tense does indeed seem to hold, this is only partial, superficially manifested as partial overlapping.

A third problem has to do with the observation that COMP-that seems to duplicate $i-T$ in $C$, a problem that $\mathrm{P} \& \mathrm{~T}$ get round by assuming a kind of resumptive function similar to that of pronouns (P\&T 2001: 388). But this is a curious possibility in the light of the the fact that in matrix interrogatives T-to-C movement never results to such duplication, even under contrastive emphasis:

(27) *What did you SAID?

What is concluded then is that there must be a distinctive difference between auxiliary inversion and the presence of that in C, to be explained through some qualification that admits only a partial overlapping, either 
in the trigger or the implementation of the operations relevant to their occurrence in $\mathrm{C}$.

\subsection{Selection as a first pointer at a qualification}

In the light of the necessity for some qualification, consider (28) where extraction of the wh-object from an embedded interrogative has taken place but T-to-C Movement is not observed:

(28) What did the guard know (the thief would steal??

If T-to-C Movement in wh-interrogatives were obligatory either as T-to-C movement or COMP-that in the complementizer and in declaratives either as COMP-that or subject attraction, the following problem arises. In (28), although the wh-expression has been moved and extracted from the embedded clause, T-to-C movement has not been realized at all. P\&T's way of explaining the absence of T-to-C Movement in (28) is to suppose that either simple Match of the subject or attraction of it by $\mathrm{C}$ may also have a licensing effect over the attraction of the non-subject wh-phrase in SPEC-CP of the embedded clause. This would be consistent with EPP's separation from Match assumed in $\mathrm{P} \& \mathrm{~T}$, stipulated in order to explain the variation met between $\mathrm{SE}$ and $\mathrm{BE}$ regarding the manifestation of auxiliary inversion. Accordingly, in embedded clauses in SE where EPP is inoperative, Match of the subject can have a licensing effect over wh-extraction, and in BE where EPP is operative subject attraction can take place instead.

In this sense then EPP is only a sub-feature of an uninterpretable feature. This renders Match a necessary but not a sufficient condition on movement, an early insight of $\mathrm{P} \& \mathrm{~T}$ into the - in principle - optional character of EPP's occurrence and its partial separation from Internal Merge. This qualification aims at cases where Match is manifested as valuation of the goal not followed by movement. This creates a featural geometry whereby Match licenses Move but does not require it. Featurally speaking, the uninterpretability of a feature licenses the occurrence of EPP but does not enforce it: 
(29)

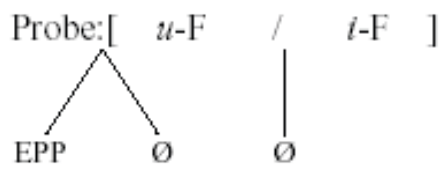

The problem that arises regarding the conceptualisation of EPP as a dependent feature though is that it lacks a derivational motivation: in other words it is itself not syntactically licensed. This in turn runs into problems, given the optionality of T-to-C movement itself in a single dialect like BE. How can we accommodate this variation within an already variational pattern solely based on the parametrised application of EPP as shown in (30)?

matrix

embedded

\begin{tabular}{|c|c|c|}
\multicolumn{1}{c|}{ SE } & \multicolumn{2}{c|}{ BE } \\
\hline$\sqrt{ }$ & \multicolumn{2}{|c|}{$\sqrt{ }$} \\
\hline $\mathrm{x}$ & $\sqrt{ }$ & $\mathrm{x}$ \\
\hline
\end{tabular}

We have to resort to a completely unrestricted operational satisfaction that in Pesetsky and Torrego in principle can take the form of an otherwise invisible subject movement, or T-to- $\mathrm{C}$ movement manifested as complementiser that:

(31) What do you think (CP Mary said)?

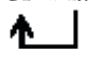

(32) What do you think [that Mary $i$-T said]?

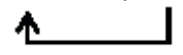

How plausible is such an unsystematic identification between two so disparate operational means? Furthermore, how plausible is the classification of the facts solely based on a parametric variation of EPP forced by the generalization of the application of T-to-C Movement in all types of clauses? This is the step taken by $\mathrm{P} \& \mathrm{~T}$, whose analysis implies the burden of explaining away the ban over the application of T-to-C Movement 
as a secondary stipulation, postulating a parametric application of EPP: $u$-T in BE bears an EPP feature triggering T-to-C Movement, whereas in SE it does not.

But here two observations are in order. First, an unqualified operational Move-to-Match extension would predict that the same conditions hold of Matrix Wh-Interrogatives where subject-Match would suffice for (33) to be grammatical:

Agree as Licencing

* (CP What $\{C\}$ the thief stole

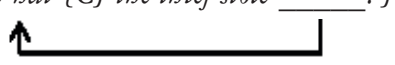

Second, an unqualified featural extension of $i$-T to COMP-that would predict that in accord with the grammaticality of $\mathrm{BE}$ examples where that and $i$-T alternate freely in embedded contexts, (34) in BE should be grammatical too:

(34) *Which tablet that the thief stole?

Crucially, (34) is altogether ungrammatical both in SE and BE. In embedded contexts instead, (34) can appear to display dialectal variation in its grammaticality between SE and BE. The observations then above as well as the schema depicted in (30) point at a more elaborate schema, regulated by a condition informally stated in (35), to be elaborated further as we proceed:

(35) The context of selection in wh-interrogatives widens the operational matrix that comprises the possibility [i-T] so as to include [COMP-that] too.

This is an interesting finding, in the sense that it argues for an endosystemic condition that opens up the operational possibilities expressed as dialectal variation. In terms of descriptive adequacy then, if we want to develop a unified account of both SE and BE data, what must be formalised is not the absence of T-to-C Movement in embedded clauses in contrast with matrix ones, but the optionality of it in embedded clauses in contrast with the obligatoriness of T-to-C Movement in matrix interrogatives, as (36) shows: 
(36)
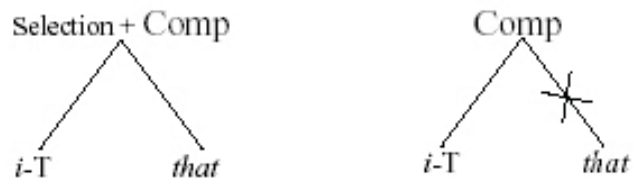

What (36) essentially corresponds to is the extension of what has been called above Comp-Tense relatedness so as for the latter to include Match in addition to Move. What has to be seen is how this operational qualification extending the complementiser's paradigm from $i$ - $T$ to COMP-that can be qualified featurally too, integrating into it the following observation: uninterpretability of a feature licenses the occurrence of EPP but interpretability of it bans EPP, or in more derivational terms "closes" the operational path that leads to EPP's application:
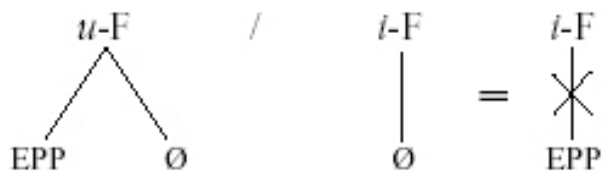

\section{Head Movement as modular operation ANd PHRASAl EXTRACTION}

3.1. Wh-CP extraction and the blocking effect of Tense

Let's start considering the extraction of an embedded wh-interrogative to a higher domain attracted by a finite T-Head, as in (38):

(38) (What the thief will do\} is unknown.

A problem arises as to the featural trigger of the movement. Prior to the raising of the wh-CP, the distribution of Tense in the structure is as follows:

(39) ... ( $T \mathrm{i}-T)$ (vP is unknown (CP what the thief will dot). 
Accordingly, the CP-structure of the clause what the thief will do prior to its raising displays the following featural composition in its $\mathrm{C}$-head:

(40) $\{C \mathrm{v}-T, \mathrm{v}-w b\}$, $(T P$ the thief $\{(T$ will $),(v P$ do what $\}\}$.

By the time the embedded CP comes to completion, all the uninterpretable features must delete for convergence. Otherwise, along with CP's raising they will be inserted undeleted into the next derivational cycle, namely the next phase. This would induce a crash either in the phonological component of the embedded phase or in the semantic component of the higher one. The same holds of $v$-T in C. In any other case, a feature with no contribution to the semantic component will remain undeleted and thus the derivation will not converge. But contrary to this prediction, the embedded $w h-\mathrm{CP}$ is allowed to be attracted by (the features of) a higher $\mathrm{T}$, thus forming a TP-Specifier in a higher domain on a different computational cycle:

... [TP $[\mathrm{CP}$ what $[\mathrm{C} v=\mathrm{wh}, t=\mathrm{T}]$ [the thief will dolf $[\mathrm{T}$ is $i$-T $][\mathrm{vP}$ is unknown...

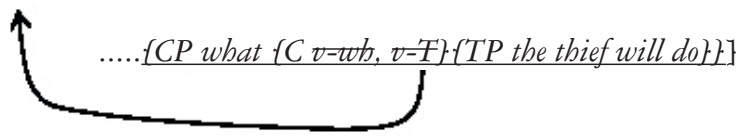

The exact problem concerns the manner in which Tense is formally involved in the attraction of the embedded CP. Uninterpretability of probefeatures is held to be the key requirement for Match to be implemented. Furthermore, although uninterpretable features are not related to Move through strict necessity, EPP operates in conjunction with the features that have triggered Match in a unidirectional relation of dependency, which are by hypothesis uninterpretable. In this connection, let's take a closer look at the value of Tense in the featural matrices of matrix- $T$ and embedded-C involved in (38-41) above:

$$
\text { ... } \left.\left[\text { i- }{ }^{\mathrm{T}}\right]\left[\text { what }\left[v^{\mathrm{C}}\right] \mathrm{T}^{-}\right] \text {the thief will do }\right] \text { is unknown. }
$$


Matrix $\mathrm{T}$ bears an $i$-T proper to its category and $\mathrm{C}$ bears a valued uninterpretable Tense feature. The initiation of a Match relation is always mediated by an uninterpretable feature that requires a matching interpretable (or valued in P\&T's sense) pair, capable of valuing the defective feature. If a matching relation of any kind is not established between $\mathrm{T}$ and $\mathrm{C}$ then EPP remains inactive, at least in English where EPP in T works mostly in conjunction with Agree. ${ }^{4}$ It follows, then, that the interrogative $\mathrm{CP}$ will not be attracted and no Movement will take place. P\&T, in order to retain the generalisation over the licensing effect of the occurrence of Tense in $\mathrm{C}$, argue that wh-CP extraction may fall into a specific case, due to the occurrence of some $\phi$-features possibly borne by the wh-expression and matched by the $u-\phi$ features in matrix T. But the specificity of this case is actually assumed to lie in the ability of a valued Tense feature in the head of a wh-CP to enable the latter to move. A disjunction of preconditions appears to hold in order for an embedded CP to move, summarized as follows:

(43) i. The Tense in $\mathrm{C}$ is interpretable occurring in $\mathrm{C}$ after T-to-C Movement has applied (in clauses like "that the thief stole the statuette").

ii. The Tense in C is uninterpretable but not endowed with an EPP feature (Embedded wh-interrogatives like "what the thief stole" contra embedded declaratives lacking COMP-that like "... the thief stole the box").

Let's have a closer look at (i), the first member of the disjunction. If both $\mathrm{T}$ and the lower $\mathrm{C}$ bear an interpretable Tense feature, then any matching between them is theoretically untenable and consequently irrelevant to the movement of the CP. The occurence of Tense in $\mathrm{C}$ somehow becomes an operationally unmotivated condition. This way it is losing its organic role in the derivation, which is precisely one of the motivations of inclusive minimalist analyses. There is no relation established between T's $i$-T and C's $i$ - $\mathrm{T}$, so the condition on extraction cannot refer to any Match relation but solely to the interpretable nature of Tense itself in C. On the other hand, (ii) refers to a condition that, although satisfying more standard assumptions on the asymmetry of probe and goal in terms of interpretability, deprives it from any operational significance insofar as it unifies it with what is stipulated in (i) which in its essence is opposite to (ii). The condition on Tense then as conceived in (43) must be reformulated so as to coherently correlate the following: the relevance of Tense for Move on the one hand,

4. Perhaps not in Locative Inversion: In the middle of the room sat a frog. 
and an appropriate qualified and distinct operational technology generated by mere Match on the other.

As we saw, in P\&T the reasoning behind the possible absence of EPP in a raising $w h-\mathrm{CP}$ is actually disconnected from the very reasons behind this ability. It follows as a consequence of this very fact that SE examples like the following point to the absence of T-to-C Movement in embedded $w h$ CPs, where nothing seems to justify a generalized licensing condition:

(44) He wouldn't guess (CP what the thief stole).

Consequently, wh-CP raising must be featurally not conflicting with the licensing condition holding of the extraction of the wh-expression what before CP-raising. Subsequently, this can plausibly be assumed to be mere Match between $u$ - $\mathrm{T}$ in $\mathrm{C}$ and $i$ - $\mathrm{T}$ in $\mathrm{T}$ in the embedded wh-CP. Additionally, as we can notice, (ii) above serves to accommodate SE examples where $u$ - $T$ is not endowed with EPP. But if we shift the reference point of the analysis to $\mathrm{BE}$ data that has precisely been the principal motivation for the stipulation of T-to-C Movement as a generalized operation, we observe the following: wh-CP extraction in the case of $\mathrm{BE}$ data is not featurally compatible with the same licensing condition as that holding of the extraction of the whexpression alone before CP-raising. This is so, because although T-to-C Movement is allowed in embedded wh-CPs in BE, T-to-C Movement is obligatorily absent when a $w$-CP raises:

(45) *? (What had the thief stolen) was not known.

That means that for BE too (ii) must hold. But this in effect nullifies the reason behind the postulation of $[+\mathrm{EPP}]$ parametrisation as a determinant of the behaviour of the BA examples. It looks more plausible to assume that uniformly BE and SE examples alike obey the same conditions on CP'raising which in general is incompatible with T-to-C Movement.

It is clear that the asymmetry between SE and BE does not simply concern a dialectal variation regarding the absence of EPP in the embedded wh-CPs in SE. Instead, what is at stake is a condition more deeply embedded into grammar, which, although allowing dialectal variation when a wh-CP is embedded, dramatically reduces the ability for variation when a wh$\mathrm{CP}$ raises into subject position. I argue then that beyond any taxonomic 
stipulation of a variational classification what is needed resembles a more dynamic featural/operational hierarchy of some sort. The latter follows a) a careful refinement of the licensing of CP-extraction that includes in its definition a more comprehensive use of the distinction between T-to-C Movement and mere Match and b) its systematic correlation with what has been said above on the relevance of the structural context of selection to the observed operational sub-choices.

Regarding (a), a possibility arising from the above observations is: T-to-C movement must be seen not as a licensing condition on $\mathrm{CP}$ extraction, but actually as a blocking mechanism that disallows CP-raising into a higher domain. T-to-C movement as a specific instance of Head Movement then constitutes a syntactic operation preceeding further embedding. The blocking role of an otherwise permissible operation occurs within the syntactic generation of the higher operational cycle, namely the matrix $\mathrm{CP}$, in which the raised CP is embedded. The system proceeds by (non)/ application of T-to-C Movement, a phenomenon apparently freely applying in $\mathrm{BE}$, and further CP-raising is dependent on the previous derivational choice. As shown in (42), this is how we can account for the contrast between the dialectal optionality of T-to-C Movement in embedded domains on the one hand and the obligatoriness of its absence within embedding domains on the other:

$$
[[\mathrm{C}], \therefore[\mathrm{T}]] \text { embedded domain }
$$

unconstrained application of T-to-C Movement
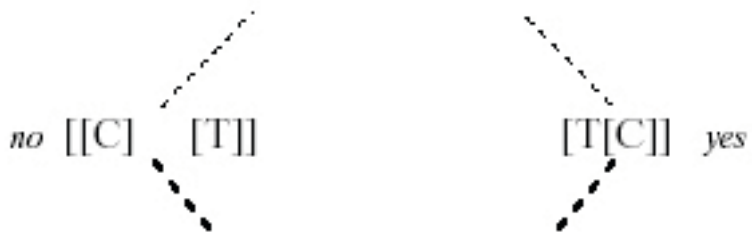

constrained application of CP-raising

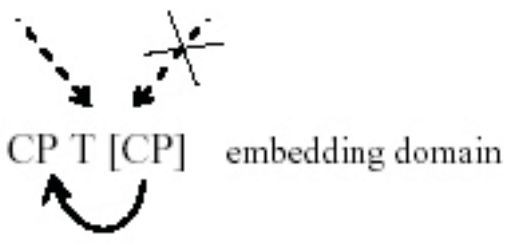


In the light of what has been said above on clause (i) of the precondition and taking the hypothesis that T-to-C Movement in an embedded clause actually blocks further CP-movement, we can now see this precondition as reflecting an effect which is the reverse of what it originally points to. According to $\mathrm{P} \& \mathrm{~T}$, although Match has been triggered between $u$ - $\mathrm{T}$ in $\mathrm{C}$ and $i-\mathrm{T}$ in $\mathrm{T}$ in embedded wh-interrogatives, EPP is not part of the featural matrix of $\mathrm{C}$. This prevents $\mathrm{T}$ from actually moving into $\mathrm{C}$. Given that the absence T-to-C Movement is generally taken by P\&T to block $\mathrm{CP}$-extraction, the two clauses of the precondition ultimately attribute the same effect to two seemingly contradictory claims: the presence of $i-\mathrm{T}$ in $\mathrm{C}$ in the case of embedded declarative extraction of CPs headed by "that", and the absene of $i$-T in the case of embedded wh-CP extraction. I argue then that the premise about the effect that T-to-C Movement has must be reversed from licensing to blocking, as stated in (47):

(47) The Blocking effect of T-to-C Movement

T-to-C Movement blocks CP-extraction

(47) intends to formulate a disjunctive precondition over movement that draws a sharp disjunction between a) the absence of $i$ - $\mathrm{T}$ in $\mathrm{C}$ and $\mathrm{b}$ ) the ocurrence of $i-\mathrm{T}$ in $\mathrm{C}$ resulting from T-to-C Movement, elaborated in the next section. This on the one hand helps us unify the technology between wh-CP and "that"-CP raising, dispensing with the necessity of stipulating a conflicting parametrized application of EPP. On the other hand, it incorporates the asymmetry between SE and BE in a hierarchy where dialectal variation is motivated endo-systemically.

\subsection{Untangling $v-T$ and $i-T$ within an operational bierarchy}

It follows from the foregoing discussion that although the featural geometry of licensing is indeed embedded in the more general context of Match between $u$ - $\mathrm{T}$ in $\mathrm{C}$ and $i$ - $\mathrm{T}$ in $\mathrm{T}$, this should be amended so as to accommodate the reverse premise over the role of $i$-T in CP-extraction as depicted in (48): 
(P\&T)

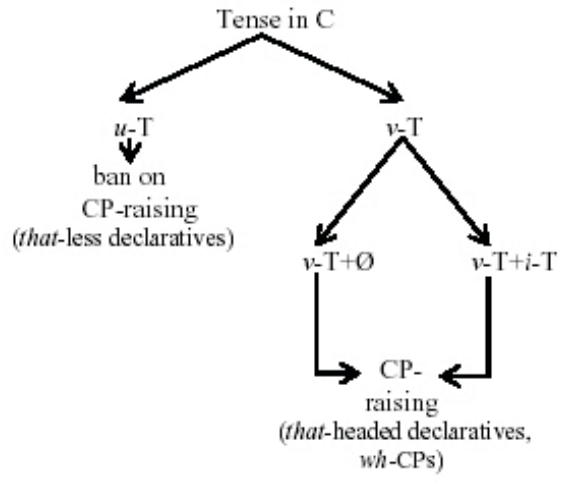

(amended version)

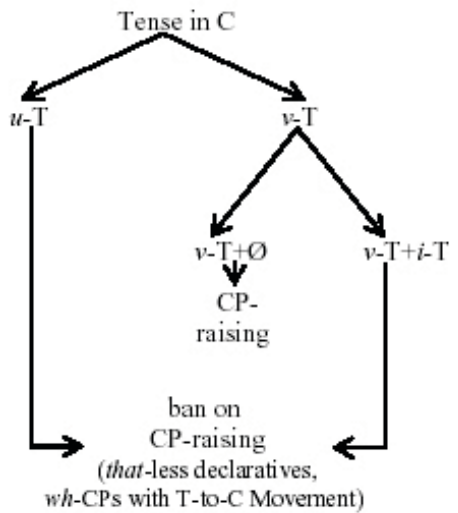

Crucially, in the amended version, both complete lack of Tense in $\mathrm{C}$ represented as $u$-T as well as interpretable Tense following T-raising represented as $v$ - $\mathrm{T}+i$-T result in ban on CP-raising. As we will shortly see, the licensing geometry both empirically and conceptually makes more sense if re-organized around the contrast between $v$-T + EPP and $v$-T. We will also see the underlying reasons that render the parallelism between $u$-T and $v-\mathrm{T}+i$-T in terms of operational outcome - i.e. ban on extraction $-\mathrm{a}$ more coherent formulation, laid down in terms of featural specificity.

We saw that free variation between Tense and COMP-that is indeed attested in embedded Interrogatives in BE:

(49) I don't know (which suitcase did the thief pick)

(50) I don't know (which suitcase that the thief picked)

A first observation is that COMP-that seems to duplicate $i$-T in $\mathrm{C}$, a problem that as we saw $\mathrm{P} \& \mathrm{~T}$ get round by assuming a kind of resumptive function similar to that of pronouns. A second is that the free variation observed in embedded clauses is not found in matrix interrogatives:

(51) Which suitcase did the thief pick?

(52) *Which suitcase that the thief picked? 
Again, there can be observed an organized distribution of Tense and COMP-"that" which in some cases is in principle overlapping $(49,50)$ and in others mutually exclusive $(51,52)$. This distribution between $w h+$ that and $w h+\varnothing$ precisely parallels that between the presence and absence of T-to-C movement. In embedded contexts, $w h+$ that is in principle unconstrained and thus allows for dialectal variation which is indeed attested. In the conext of matrix clauses and Spec-TP though, the free variation is severely constrained so that the possibility of dialectal variation disappears.

Inquiring into the hierarchy of operational dependences then alluded to above, a plausible organization of the structural space locates the freely alternating occurence of COMP-"that" and Tense higher in this hierarchy, assuming an operational paradigm following the direction non-specified $\rightarrow$ fully specified, where crucially the structural context of selection represents the less specified derivational point:

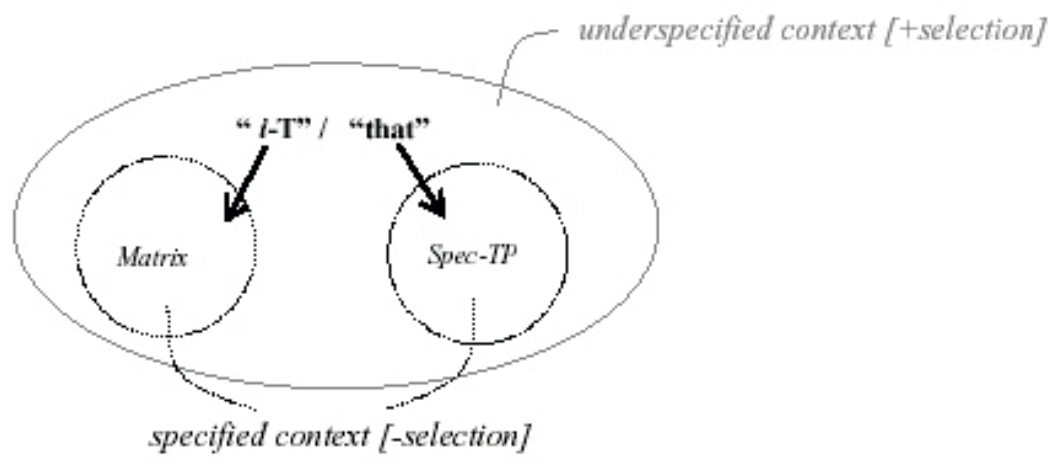

The question that arises to this connection is what is the operation that regulates this "narrowing" of the operational sub-choices to a qualified hierarchy of possibilities? Additionally, what is its correlation with the structural context of selection?

Towards an analysis of Move in general as an operation that is driven by requirements somehow linked with effects recognisable by the semantic compopnent, both A and A'-Movement have been analyzed in these terms. Instances of "criterial freezing effects" like subject's immobility (ef.: Rizzi 2006: 98) have been accounted for as resulting from a constituent reaching 
a criterial position dedicated to its interpretation. What I argue is that the separation of Match and EPP envisaged in P\&T indeed points at an essential split between matching and the saturation of the features involved in it. In this light, specific architectural parallels can be drawn between head and phrasal movement, but holding on a different operational scale. These parallels concern a tripartite featural saturation of a head into $[u-\mathrm{F}]$, $[v-\mathrm{F}]$ and $[i-\mathrm{F}]$.

I essentially adopt here a conceptualisation of selection along the lines of Matushansky (2006), where the locality restriction on head movement (Travis 1984) is treated as the operational correspondence of a lexical restriction on c-selection. The reference to the structural context of selection (see above) precisely intends to accommodate the latter as the syntactic realisation of c-selection. Accordingly, c-selection is assumed to be to head movement what Agree is to phrasal movement (Matushansky, op.cit; for a similar analysis see Pesetsky and Torrego 2006), whereby a head selects the syntactic category of the head of its complement. Feature matching is the syntactic reflex of this process. The specific requirements on locality are what give to head relations the status of a quasi-modular process, with both c-selection and head movement being part of the same operational cycle. As said above, an interesting possibility arises when phrasal movement appears to be contingent upon the way head relations are syntactically processed. In the case of Complementizer-Tense relation, this operational cycle, "procedure" in the wording of Matushansky (2006), creates a syntactic domain, which depending on the degrees of completion of T-to-C Movement's modular operational cycle can "open” distinct subchoices of phrasal movement.

The general ban on the excorporation of a moved head (e.g. Roberts 1991) is a characteristic that co-aligns the freezing effect assumed for phrasal movement, if head movement is attributed to an interpretability requirement akin to that holding of phrasal movement. Concretely, the valued uninterpretable feature $v-\mathrm{F}$ in a head-pair A-B containing $[i-\mathrm{F}]-[v-\mathrm{F}]$ has been localized with its interpretable counterpart $i-\mathrm{F}$, thus becoming interpretable by locality. Insofar as merge has been implemented rendering $v$-F interpretable, the moved consituent cannot move further, being freezed at the site where it has incorporated: 


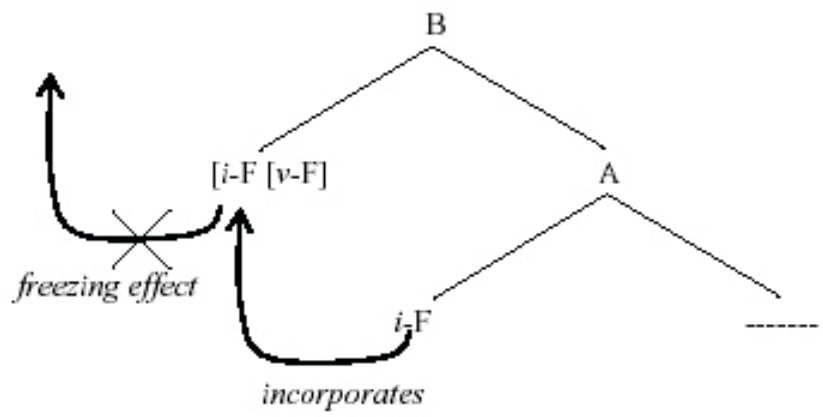

This view at head movement has the virtue of locating parallels with phrasal Agree and Move in the light of the separation of Match from EPP, at the same time retaining the modular characteristics of head movement as a weakly distinct dimension embedded in the syntactic system. I take this partial dissociation of Agree and EPP hinted at in Rizzi (2004a, b) and in P\&T $(2001,2004)$ to point to something substantial in the system. In the context of my current analysis, a tentative attempt is made to map the interpretive relevance of these projections into the operational subcomponents of a single cycle. I suggest then that Match/Move should be better partitioned into two separate operations, namely Valuation/EPP. Each of them corresponds to distinct degrees of interpretive completeness, which are not lnked with each other through necessity, but through an operational dependency. This interestingly gives a greed-like (Chomsky 1995) flavor to EPP (the second element of the Agree/Move partition), that actually serves the enlightened self-interest (Lasnik 1999a, b) of the goal, in the guise of an EPP feature usually formulated as a property carried by the probe. So, instead of identfying Attract with EPP as an operation initiated by the probe, my analysis assumes identification between Move and EPP. EPP is Move, and no difference exists between them:

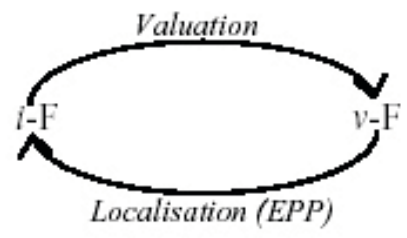


The EPP-Move identification aims precisely at dispensing with the sub-featural character of EPP, which follows as a consequence of the lack of generalised applicability. It intends to say that the satisfaction of EPP does not target a featural need of a probe but contributes to a featural stability of a more global character including both probe and goal. This assumption is in theoretical accord with efforts directed towards a desirable entire elimination of EPP, an otherwise ad hoc stipulation.

But what about EPP insofar as phrasal movement is concerned, precisely for which EPP was first stipulated? Regarding wh-movement, dispensing with EPP has the welcome result that a greed-like movement of a wh-expression is consonant with the lexicosemantic properties of it, more felicitously formulated as referential indefiniteness/underspecification (see Ioannou 2012 for more on this possibility, also Katz \& Postal 1964). In this sense, what triggers wh-movement is a phrase's need to structurally express this referential underspecification that results to interrogative interpretation by occupying the proper position in the CP domain (Chomsky 2008) and is not inherent on the wh-expression itself. In this light, nothing indeed necessitates that EPP be part of the probe but in contrast it is directed towards the A'-like needs of the goal. Intermediate landing sites get a more satisfactory treatment too, either as part of an independent requirement like successive cyclicity (Bošković 2002) or of the enlightened self-interest of the expression itself, possibly constrained by locality.

Regarding A-movement, cases that have to be put under inspection in the light of the current formulation are the ones that touch upon the issue of insertion vs. movement, like the external merge of expletives as in the following examples:

(56) The theaf is in the garden.

(57) There is a thief in the garden.

How can somebody accommodate the insertion of expletive "there" if not as an inherent property of $T$ ? Without attempting a detailed treatment of such crucial cases, something that would lead us astray from the matter of the present analysis, I tentatively argue the following: if the presence of the subject has to contribute to the predicational saturation of a clause 
(cf. Rohstein 1983) $)^{5}$, then the very fact that "there" in (53) needs to be associated with "the thief", the logical subject of the clause, shows that indeed SPEC-TP satisfies the logical noun's requirement for some overt association (Lasnik 1992, 1995) with it. In this light, further specific parallels can be drawn between "that"-headed CPs and "there"-TPs, if both are conceived as representing a mid-way stage in the derivational cycle of featural saturation refered to above. I leave this interesting issue as a matter open to further research.

\subsection{Degrees of completion and phrasal pied-piping.}

Seeking to incorporate EPP as a feature that is part of a dynamic interplay between two heads, what thus far was formulated as an occurence of $i$ - $\mathrm{T}$ in $\mathrm{C}$ as opposed to $v$ - $\mathrm{T}$ in $\mathrm{C}$ dynamically can be defined as $v$-T $+\mathrm{EPP}$. Consequently, the featural geometry depicted in (48) above takes the following form:

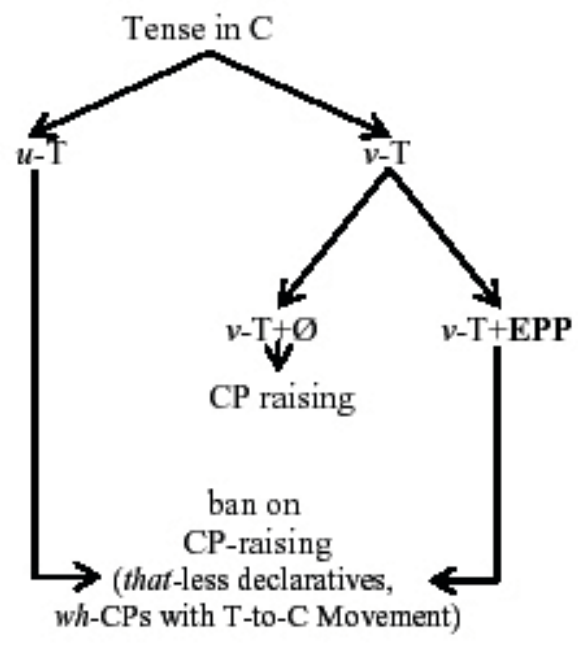

5. A vP-oriented notion that precisely reflects the involvement of semantic considerations in the initial formulation of EPP as Extended Projection Principle, in accordance with what I have said immediately above regarding wh-movement. 
As we see in (58), $u$-T and $v$-T + EPP are identified regarding their operational output. The hierarchy above is consistently paralleled by the schema depicted in (59), where Head Movement completes the degrees of a tripartite cycle that originates in the Lexicon and is saturated in Syntax. EPP in turn, although contributing to the interpretability of the valued $v$ - $\mathrm{T}$ feature in $\mathrm{C}$, leads to an interesting result following the identification of $v$-T with $i$-T:

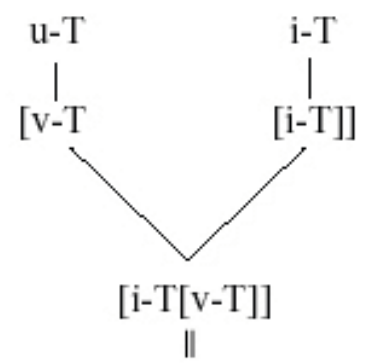

[i-T] Identification through value-identity

Interpretatively, $i$-T absorbes $v$-T, leading to the deletion of the latter as being indistinguishable from $i$ - $\mathrm{T}$ in accordance with some version of the Identity Avoidance Principle (Riemsdijk 1998, 2008). This process results in $i$ - $\mathrm{T}$ being the only feature projecting onto $\mathrm{C}$, but also in a further consequence: the elimination of the minimal selectional domain.

We saw that when it applies in embedded interrogatives, T-to-C Movement bans CP-raising. We also saw that the domain of selection is the structural context where dialectal variation is permitted. These possibilities correspond to what was represented as "narrowing" of the featural relation between $\mathrm{C}$ and $\mathrm{T}$ in the structural context of selection. Here is where the notion of underspecification comes into play, if seen as a mid-point of the saturation process of the tripartite sisterhood cycle. The blocking effect of T-to-C Movement over CP-extraction lies at the end of it, and the licencing effect that valuation has over CP-extraction at the middle of it. Accordingly, both Match and Move are in principle possible at this stage, enabled by the featural underspecification pertaining to selection. In this sense sisterhood "curves" the path for phrasal movement to apply, but can also "close" it 
so that a higher probe is rendered blind by losing its "connected path" towards an appropriate goal.

In the light of the formulation of EPP as a greed-like property, I repeat here the constitution of the featural matrices of matrix- $T$ and embedded-C involved in a sentence like what the thief will do is unknown before the wh-CP raises into the matrix clause:

(1)

$$
\ldots\left[{ }^{\mathrm{T}} \mathrm{-T}\right]\left[\text { what }\left[{ }^{\mathrm{C}}-\mathrm{T}\right]^{-} \text {the thief will do }\right] \text { is unknown. }
$$

With the matrix $T$ bearing an $i$-T proper to its category and embedded $\mathrm{C}$ a $v$-T, the greed-like requirement of $v$-T for interpretability can in principle be satisfied in two ways: raising of $w h-\mathrm{CP}$ into the local domain of $i-\mathrm{T}$, or raising of the $i$-T head of the embedded clause into $C$ itself. Why is it the interpretable feature that in principle can raise in the second case? An important asymmetry is at stake here that has to do with the symmetric character of c-command between two sisters. Adapting Kayne's (1994) antisymmetry formulation in order to accommodate the linearisation requirements between heads, we observe that the symmetric nature of the c-command between heads fails to yield directional head movement. This is so because insofar as Internal Merge is concerned, the latter must make use of asymmetric c-command to yield its directionality which surfaces as if implemented leftwards:

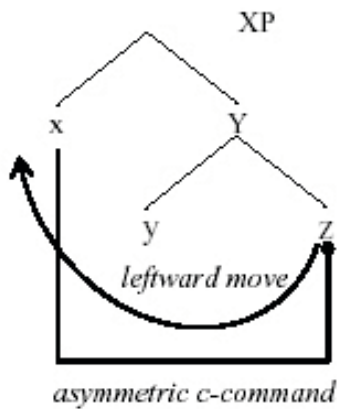


In contrast, in a relation between heads that retain the modular transparency of their relation throughout a derivation (ef.: Chomsky 2000: $117)$, c-command is crucially symmetric. This consequently renders the potential for bidirectional move:

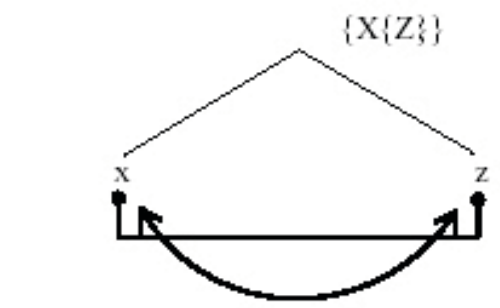

symmetric c-command and bidirectional move

Featural identity and symmetric c-command can result in movement under the requirement that a valued uninterpretable feature must be optimally close to its interpretable counterpart. The selectional featurematching between $u$ - $\mathrm{T}$ in $\mathrm{C}$ and $i$ - $\mathrm{T}$ in the embedded $\mathrm{T}$ has been satisfied upon selection and has created what Matushansky calls a "procedure of selection", a process whose character this analysis extends. Matushanski's (2006: 78) conception of selection limits the process to the binary pair projecting/no projecting head, making use of Transparency Condition:

(4) Transparency Condition

A head ceases to be accessible once another head starts to project.

The current analysis extends on this conceptualization by recognizing the relevance of Agree and Move over the projection of $\mathrm{X}$ or $\mathrm{Z}$ within a head pair $\{X\{Z\}\}$ that in principle stands in a symmetric relation rearding c-command (contra Matushansky 2006: 77-8). Selection of a head Z by a head $\mathrm{X}$ does not lead to automatic inaccessibility of $\mathrm{Z}$. In the case at hand, this is evident in the ability of T-to-C Movement to apply even after an embedded $\mathrm{C}$, itself selecting a lower $\mathrm{T}$, has been selected by a matrix $\mathrm{V}$ :

$$
\{\mathrm{C}\{\mathrm{T}\}\} \rightarrow\{\mathrm{V}\{\mathrm{C}\{\mathrm{T}\}\}\} \rightarrow\{\mathrm{V}\{\mathrm{T}\{\mathrm{C}\{\mathrm{T}\}\}\}\}
$$


The fact that the set $\{\mathrm{T}\{\mathrm{C}\{\mathrm{T}\}\}$ cannot be extracted but $\{\mathrm{C}\{\mathrm{T}\}\}$ can implies that the binary opposition project/not project must be extended so that it includes the syntactic relevance of both. This must not refer only to the relevance of categorial selection (c-selection) between heads that proceeds in a linear upward fashion rendering, but also a) to the reprojection between $\{C\{T\}\}$ surfacing as $\{T\{C\{T\}\}\}$, and $b$ ) the operational stage lying "in between", which is Agree, or differently Match without Move.

Chomsky's requirement on strict cyclicity (1995) forces strong features to be checked immediately upon being introduced into the derivation. This requirement must be relaxed so that it includes the operativeness of the non application of head movement. This is precisely the case of CP extraction. Holding the notion of Selection as a procedure in the sense of Matushansky, consider what happens when selection coincides with Agree, namely the case of $\mathrm{C} / \mathrm{T}$ selection: in case this relation is not checked off by actual movement, Agree creates a dependency that leads to pied-piping. A relation between $i$ - $\mathrm{T}$ in matrix $\mathrm{T}$ and $v$ - $\mathrm{T}$ in embedded $\mathrm{C}$ is established before the $\mathrm{C}$-head checks its features by movement of $\mathrm{T}$. In other words, probing between $\mathrm{C}$ and $\mathrm{T}$ is still holding. This creates a dependency that leads to extraction of the whole CP-complement when $v$-T seeks to satisfy its greed-like property through raising into matrix $\mathrm{T}$ :

(6)

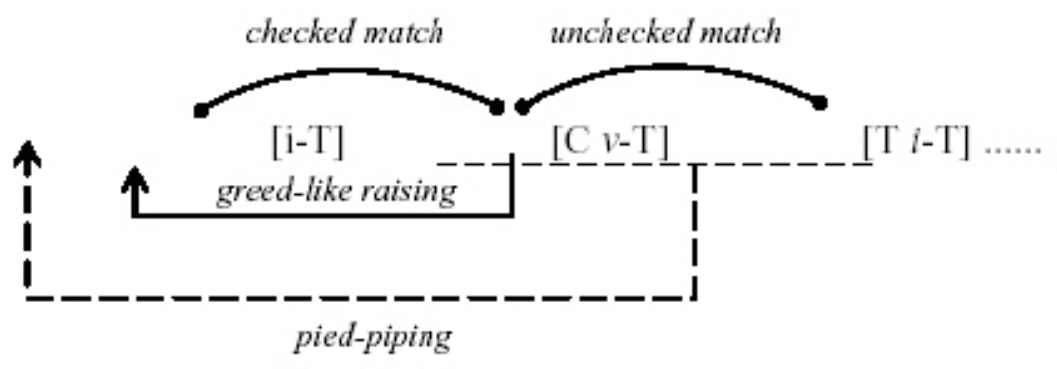

\section{Conclusions}

This paper examined the licensing effect attributed to T-to-C movement as a condition on phrasal extraction. Taking a closer look at the syntactic effects of T-to-C Movement, it concluded that the effect that 
T-to-C Movement actually has over the extraction of a CP-unit wherein it applies should be reversed from that of licensing to blocking. This brought valued Tense features in $C$ into sharp operational contrast with interpretable ones appearing in $\mathrm{C}$ after T-to-C Movement applies. Elaborating on the consequences of this observation, my analysis outlined a schema of head-relations seen as a tripartite cycle comprising various degrees of completion, represented by corresponding featural saturation: $u-\mathrm{T}, v-\mathrm{T}$ and $i$-T respectively. In this featural geometry, $v$ - $\mathrm{T}$ and $i$-T born by the headpair C-T before T-to-C movement applies were analyzed as a relational domain of symmetric c-command and incomplete saturation, lying at a derivational point of featural underspecification. This property was linked with selection and was considered to be the reason for the - in principle optional character of the application of T-to-C Movement in embedded whdomains, stabilized in time as dialectal variation. Employing the definition of head relations as a procedure used in Matushansky (2006), CP raising was interpreted as phrasal pied-piping resulting from incomplete saturation of the head-pair domain. In turn, the banning on it was attributed to the elimination of the sisterhood domain following T-to-C Movement. The latter, although contributing to the interpretive completeness of the C-T cycle through head movement reminiscent of Rizzi's criterial phrasal raising, it also leads to the elimination of the selectional domain, disconnecting it from any higher probe.

Recebido em dezembro de 2012 Aprovado em julho de 2013 E-mail: gi_io@yahoo.gr

\section{REFERENCES}

ABELs, Klaus. 2003. Successive cyclicity, anti-locality and adposition stranding. Doctoral Thesis. Stors: University of Connecticut. [on line] http://ling. auf.net/lingbuzz/000049 [17/06/2013].

Agbayani, Brian. 2000. Wh-subjects in English and the vacuous movement hypothesis. Linguistic Inquiry 31: 703-13.

BošKović, Željko. 2002. A-movement and the EPP. Syntax 5: 167-218. Chomsky, Noam. 1981. Lectures on Government and Binding: The Pisa Lectures.

Dordrecht: Foris. . 1986. Barriers. Cambridge, Mass: MIT Press. 
1995. The Minimalist Program. Cambridge, Mass: MIT Press.

. 2000. Minimalist Inquiries: The Framework. In: Roger Martin, David Michaels \& Juan Uriagereka (eds.) Step by step: Essays in syntax in honor of Howard Lasnik. Cambridge, Mass: MIT Press, pp. 89-155.

. 2001. Derivation by Phase. In: Michael Kenstowicz (ed.) Ken Hale: a Life in Language. Cambridge, Mass: MIT Press, pp. 1-52.

. 2002. On Nature and Language. Cambridge: Cambridge University Press, Cambridge.

. 2008. On Phases. On Phases. In: Robert Freidin, Carlos P. Otero \& Maria Luisa Zubizarreta (eds.) Foundational Issues in Linguistic Theory: Essays in Honor of Jean-Roger Vergnaud. Cambridge, Mass: MIT Press, pp. 133-166.

Henry, Alison. 1995. Belfast English and Standard Englilsh: Dialect variation and parameter setting. Oxford: Oxford University Press.

Hinzen, Wolfran. 2006. Mind Design and Minimal Syntax. Oxford: Oxford University Press.

IoAnnou, Georgios. 2012. Wh-features and the Lexicon/Discourse Interface. Lenguas Modernas 39: 45-68.

Katz, J. Jerrold \& Paul, M. Postal. 1964. An Integrated Theory of Linguistic Descriptions. Cambridge, Mass: MIT Press.

Kayne, Richard Stanley. 1994. The Antisymmetry of Syntax. Cambridge, Mass: MIT Press.

LASNIK, Haward. 1999a. Chains of Arguments. In: Samuel David Epstein \& Norbert Hornstein (eds.) Working Minimalism. Cambridge, Mass: MIT Press, pp. 189-215.

. 1999b. Minimalist analysis. Cambridge, Mass: MIT Press.

LASNIK, Howard \& Mamoru Saito. 1999. On the subject of infinitives. In: Howard Lasnik. Minimalist analysis. Malden, MA: Blackwell, pp. 7-24.

Matushansky, Ora. 2006. Head movement in linguistic theory. Linguistic Inquiry 37: 69-109.

Pesetsky, David \& Esther Torrego. 2001. T-to-C movement: Causes and consequences. In: Michael Kenstowicz (ed.) Ken Hale: a life in language. Cambridge, Mass: MIT Press, pp. 355-426. . 2004. Tense, Case and the nature of syntactic categories. In: Jacqueline Guéron \& Jacqueline Lecarme (eds.) The Syntax of Time. Cambridge, Mass: MIT Press, pp. 495-538. 
. 2006. Probes, Goals and Syntactic Categories. In: Ykio Otsu (ed.)

Proceedings of the 7th Tokyo Conference in Psycholinguistics. Tokyo: Hituzi Syobo Publishing. Pp. 25-60.

Norvin, Richards. 1997. What Moves Where When in Which Language.

Doctoral Thesis. MIT. [on line] http://dspace.mit.edu/bitstream/ handle/1721.1/10236/38529295. pdf? sequence $=1$ [17/06/2013]. . 2001. Movement in Language. Oxford: Oxford University Press. RADFORD, Andrew. 1997. Syntactic theory and the structure of English: A minimalist approach. Cambridge: Cambridge University Press.

Riemsdijk, van, Henk. 1998. Syntactic feature magnetism: The endocentricity and distribution of projections. Journal of Comparative Germanic Linguistics 2: 1-48.

. 2008. Identity Avoidance. In: Robert Freidin, Carlos Peregrín Otero

\& Maria Luisa Zubizarreta (eds.) Foundational issues in linguistic theory. Cambridge, Mass: MIT Press, pp. 227-50.

RizzI, Luigi. 1988. On the structural uniformity of syntactic categories. In: Vitoria Gasteiz, V. (ed.) Congrès de la langue Basque, Central de Publicationes del Gobernio Vasco, pp. 89-101. . 1990. Relativized Minimality. Cambridge, Mass: MIT Press.

RizzI, Luigi. 1997. The Fine Structure of the Left Periphery. In: Liliane Haegeman (ed.) Elements of Grammar. Netherlands: Kluwer Academic Publishers, pp. 281-338.

. 2000. Remarks on early null subjects. In: Marc-Ariel Friedemann \& Luigi Rizzi (eds.) The Acquisition of Syntax. London: Longman, pp. 269-292.

. 2004a. Locality and Left Periphery. In: Adriana Belletti (ed.) Structures and Beyond: The Cartography of Syntactic Structures. Oxford: Oxford University Press, pp. 223-251.

. (Ed.) 2004b. The Structure of CP and IP: The Cartography of Syntactic

Structures. Vol. 2. New York: Oxford University Press.

. 2006. On the Form of Chains: Criterial Positions and ECP Effects.

In: Lisa Cheng \& Norbert Corver (eds.) Wh-movement, moving on. Cambridge, Mass: MIT Press, pp. 97-134.

Roberts, Ian. 1991. Excorporation and Minimality. Linguistic Inquiry 22: 209-218.

Rothstein, Susan Deborah. 1983. The Syntactic Forms of Predication. Doctoral Thesis. Cambridge, Mass: MIT. [on line] http://dspace.mit. edu/handle/1721.1/15509 [17/03/2013]. 
Sobin, Nicholas. 2002. The Comp-trace effect, the adverb effect and minimal CP. Journal of Linguistics 38: 527-560.

Travis, Lisa. 1984. Parameters and Effects of Word Order Variation. Doctoral Thesis. Cambridge, Mass: MIT. [on line] http://dspace.mit.edu/ handle/1721.1/15211 [17/06/2013]. 